\title{
CORRECTION
}

\section{RAS GTPASES: INTEGRINS' FRIENDS OR FOES?}

\section{Kayoko Kinbara, Lawrence E. Goldfinger, Malene Hansen, Fan-Li Chou and Mark H. Ginsberg}

Nature Rev. Mol. Cell Biol. 4, 767-776 (2003)

The authors wish to correct an error in the annotation of the bibliography. Reference 39 is incorrectly annotated as 'This study for the first time identified Nore1/RapL, and showed that Nore1B/RapL interacts with Rapl through a RA domain as it does with Ras and R-ras.' In the text, the identification of Nore $1 \mathrm{~B} / \mathrm{RapL}$ is correctly attributed to references 66 and 67 , and reference 39 is properly cited as showing an interaction between Norel and R-ras. The authors intended to publish reference 39 without further annotation; however, an accidental insertion of the erroneous comment occurred during a revision of the manuscript's bibliography. The online versions of this article have been corrected. 